\title{
Index General Analítico de los Números 1-32 (1967-1975)
}

\author{
preparado por Ana María Aguirre Valdivieso \\ y Maria Magdalena Cox Baeza
}

\section{INDICE POR AUTORES}

ABERASTURY, Marcelo

Asia Oriental y Meridional y el $\mathrm{Pa}$ cífico: Inicios de 1972.

ムก̃o V, No 17, p. 3 (encro-marzo 1972).

ACOSTA, Mercedes y VILAS, Carlos

María.

Santo Domingo y Checoslovaquia en la politica de bloques.

Año II, No 8, p. 565 (encro-marzo 1969).

ALMEYDA, Clodomiro

Las OLAS y la crisis politica de América Latina.

NQ 3 y 4, p. 427 (octubre 1967marzo 1968).

ARAUJO CASTRO, J. A. de

El Continente Americano dentro de la problemática mundial.

Año V, No 20, p. 3 (octubre-diciembre 1972).

AZIZ, Sartaj

Los verdaderos problemas de la crisis de alimentos.

Año VIII, No 30, p. 119 (abril-junio 1975).

BALTRA, Alberto

América Latina y la Segunda UNCTAD.

Año II, No 8, p. 449 (encro-marzo 1969).

BALL, W. MacMahon

Australia en el Pacifico.

Año V, Ne 20, p. 40 (octubre-diciembre 1972).

BAMBIRRA, Vania

La Revolución Cultural y el Marxismo.

Año II, No 7, p. 406 (octubre-diciembre 1968).

BERGSTEN, C. Fred
Relaciones económicas entre Estados Uniclos y Latinoamérica: la estructura internacional y algunos enfoques posibles.

Año VIII, Ne 31, p. 19 (julio-septiembre 1975).

BERNSTEIN, Enrique

Situación política en víspera de mayo de 1968 .

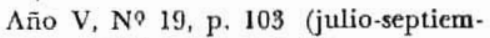
bre 1972).

BODENHEIMER, Susanne

La crisis del Movimiento Socialdemócrata en América Latina.

No 12, p. 54 (cnero-marzo 1970).

BOGNAR, Jozsef

Reforma económica en Hungria.

Año III, Ne 10, p. 107 (julio-septicmbre 1969).

BULL, Hedley

Las Rclaciones Internacionales como ocupación académica.

Año VII, No 28 , p. 76 (octubre dicicmbre 1974).

BURTON, J. W.

No-alincación y política mundial contemporánea.

Año III, No 9, p. 32 (abril-junio 1969).

BYTH, James

Niugini: una nueva nación cuprífera en el Pacifico se acerca a su independencia.

Año VI, Ne 22, p. 82 (abril-junio 1973).

CADENA, Cecilia y JOXE, Alain

Armamentismo dependiente: Caso Latinoamcricano.

Año IV, No 14, p. 3 (julio-scpticmbre 1970). 
CIRIA, Alberto

La comunicación política en América Latina: Algunos de sus problemas.

Año II, No 8, p. 530 (enero-marzo 1969).

CLARKSON, Stephen

La intelligentsia satélite: los intelectuales canadienses frente a los Estados Unidos.

Año V, No 18, p. 41 (abril-junio 1972).

CLAVERIE RODRIGUEZ, Heliodoro

L., ECHEVERRIA, Pedro Luis y

VILLALBA VERA, Jovito A.

El Tratado modificado de reciprocidad comercial entre Venezuela y los Estados Unidos.

Año V, Ne 19, p. 91 (julio-septiembre 1972).

CONSTANTINESCO, Leontin

Las relacioncs Estados Unidos-Comunidad Económica Europea en la perspectiva de la Rueda Nixon.

A.ño VI, No 21, p. 44 (enero-marzo 1973).

COTLER, Julio

Crisis política y Populismo Militar en el Perú.

No 12, p. 439 (enero-marzo 1970).

CRONER, Claos

Estudios sobre el subdesarrollo colombiano. Comentario crítico.

Año IV, No 14, p. 117 (julio-septiembre 1970).

DELGADO, Carlos

Sobre algunos problemas de Ia parti. cipación en la Revolución Peruana.

Año VI, No 21, p. 24 (encro-marzo 1973).

DEVILlers, Philippc

Francia y la Segunda Guerra del Vietnam.

Año II, No 6, p. 214 (julio-septiem. bre 1968).

DIAZ ALEJANDRO, Carlos $F$.

El Grupo Andino en el proceso de Integración Latinoamericana.

Año II, No 6, p. 242 (julio-scpticmbre 1968).

ECHEVErria, Pedro Luis, Clave.
RIE RODRIGUEZ, Heliodoro L. y

VILLALBA VERA, Jovito A.

El Tratado modificado de reciprocidad comercial entre Venezuela y los Estados Unidos.

Año V, No 19, p. 91 (julio scpticmbre 1972).

END, Heinrich

La política extcrior del gobierno Kicsinger-Brandt.

Año II, No 7, p. 358 (octubre-diciembre 1968).

FAUNDEZ, Julio.

El Sistema Intcramericano de Seguridad en la política exterior de Estados Unidos.

No 11, p. 372 (octubre-diciembre 1969).

E1 presidente de Estados Unidos y la facultad para hacer la guerra.

Año IV, Ne 15, p. 60 (octubre-di. ciembre 1970).

FERRER, Aldo

Relaciones económicas entre la Comunidad Económica Europea y América Latina.

Año VI, No 24, p. 3 (octubre-diciembre 1973).

La crisis del sistema monetario internacional. Un enfoque estructuralista.

Año VIII, No 30 , p. 48 (abril-junio 1975).

FRONDIZI, Arturo

El problema nacional de América Latina y cicrtos csquemas de integración regional.

No 3 y 4, p. 285 (octubre 1967-marzo 1968).

FOGARTY, John

Australia y el problema de las inversiones extranjeras.

Año VI, No 22, p. 106 (abril-junio 1973).

FURTADO, Celso

La concentración del poder económico en los Estados Unidos y sus proyecciones en América Latina.

No 3 y 4, p. 323 (octubre 1967marzo 1968).

Proceso y frustración de las Refor- 
mas Agrarias en América Latina.

No 3 y 4 , p. 353 (octubre 1967marzo 1968).

Una interpretación estructuralista de la "crisis" actual del capitalismo. Año VIII, No 30, p. 3 (abril-junio 1975).

GIRVAN, Norman

El conflicto de Guyana-ALCAN y la nacionalización de DEMBA.

Año V, No 19, p. 71 (julio-septiembre 1972).

Teorias de dependencia económica en cl Caribe y Latinoamérica: un cstudio comparativo.

Año VI, No 23, p. 23 (julio-sep. tiembre 1973).

GITTINGS, John

¿Tienc China una política exterior? № 1, p. 76 (abril 1967).

Libros sobre la guerra en Vietnam. No 2, p. 212 (julio 1967).

E1 Ejército Popular de Liberación y la Revolución Cultural.

Año II, NQ 5, p. 3 (abril-junio 1968).

La nueva guerra en Indochina.

An̄o IV, No 14, p. 104 (julio-septiembre 1970).

GODOY, Horacio $\mathrm{H}$.

La integración de América Latina y el proceso del poder mundial.

Año II, Ne 7, p. 368 (octubre-dicicmbre 1968).

Los Acuerdos entre los Estados Unidos y la Unión de las Repúblicas Socialistas Soviéticas.

Año VII, No 28, p. 3 (octubre-diciembre 1974).

GOT $\Gamma$, Richard

El sur de Africa y el fin de la guerra fria.

No 1, p. 95 (abril 1967).

El Congo a partir de Mobutu.

No 3 y 4, p. 443 (octubre 1967- marzo 1968).

La experiencia guerrillera en Bolivia. Año II, No 5, p. 85 (abril-junio 1968).

GRANT, BRUCE

Australia y cl Pacífico.

Año V, No 17, p. 40 (encro-marzo 1972).

GRANT, James P.

Las naciones de la OPEP: ¿Asociados o compctidores?

Año VIII, Ne 30, p. 100 (abril-junio 1975).

GUERRERO, Mauricio y SAGASTI, Francisco

Situación de la ciencia y tecnología en América Latina.

Año VII, Ne 25, p. 16 (encro-marzo 1974).

HALTY CARRERE, Máximo

¿Hacia un nucvo orden tecnológico?

Año VIII, No 32, p. 33 (octubre-diciembre 1975).

HANSEN, Roger

Relaciones cconómicas cntrc los Estados Unidos y América Latina. ¿Bilaterales, regionales o globales?

Año VIII, No 31, p. 59 (julio-septiembre 1975).

HERRERA, Amílcar O.

La ciencia en el desarrollo de América Latina.

Año II, No 5, p. 38 (abril-junio 1968).

HERRER $\Lambda$, Felipe

Viabilidad de una comunidad latinoamericana.

Año I, No 1, p. 21 (abril 1967).

La tarca inconclusa: América Latina integrada.

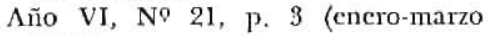
1973).

América Latina y cl desafío internacional para la educación.

Año VH, Ne 25, p. 3 (enero-marzo 1974).

HIRSCHMAN, Albert O.

Liderazgo, percepción del cambio y subdesarrollo.

Año II, No 6, p. 258 (julio-septiembre 1968).

HODARA, Joseph

La estructura internacional: cuatro versiones.

$\Lambda$ ño VIII, No 31, p. 100 (julio-septiembre 1975).

HOFFMANN, Stanley

El estilo norteamericano: su pasado, sus principios.

Año III, Ne 9, p. 48 (abril-junio 1969).

HOLBRAAD, Carsten

El papel de las potencias medias en la politica internacional. 


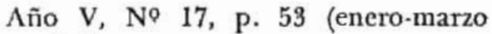
1972).

HURTADO, Héctor, PAZOS, Javier y MAYOBRE, Eduardo

El Caribe y Venezuela: integración de la integración.

Año VII, No 27, p. 3 (julio-septiembre 1974).

IMAZ, José Luis de

¿Adiós a la teoría de la dependencia? Una perspectiva desde la Argentina.

Año VII, No 28, p. 49 (octubre-diciembre 1974),

IRELAND, Rowan

La Iglesia Católica del Brasil: límites del aggiornamento.

Año VII, Ne 27, p. 76 (julio-septiembre 1974).

JAGUARIBE, Helio

El cquilibrio ccológico mundial y los países subdesarrollados.

Año V, No 17, p. 92 (enero-marzo 1972) .

Los acontecimientos chilenos.

Año VII, No 26, p. 3 (abril-junio 1974).

El Brasil y la América Latina.

Año VIII, Ne 29, p. 106 (cnero-marzo 1975).

El Vietnam y los Estados Unidos.

Año VIII, No 31, p. 3 (julio-septiembre 1975).

JOXE, Alain

Hacia una nucva concepción de la seguridad europea.

Año I, No 2, p. 156 (julio 1967).

Cohetes anticohetes: ¿Regreso a estrategias defensivas?

Año II, No 5, p. 115 (abril-junio 1968).

Doctrina estratégica y guerras de intervención.

Año II, No 6, p. 276 (julio-septiembre 1968).

¿Fin de la preponderancia estratégica norteamericana?

No 11, p. 273 (octubre-diciembre 1968).

JOXE, Alain y CADENA, Cecilia

Armamentismo dependiente: Caso Latinoamericano.

Año IV, No 14, p. 3 (julio-septiembre 1970).
KADAR, Bela

Los países pequeños en la economía mundial.

Año IV, No 16 , p. 158 (enero-marzo 1971).

KAISER, Karl

Una nueva politica oriental en Alemania.

Año II, No 8, p. 543 (encro-marzo 1969).

KALECKI, M. y KULA, Marcin

Notas sobre los aspectos sociales y económicos de los "Regímenes In. termedios"; el caso de Bolivia.

Año IV, No 15, p. 84 (octubre- diciembre 1970).

KOJIMA, Kiyoshi

Un área de libre comercio del $\mathrm{Pa}$ cifico.

Año V, No 20, p. 53 (octubre-diciembre 1972).

KULA, Marcin y KALECKI, M.

Notas sobre los aspectos sociales y económicos de los "Regímenes Intermedios"; cl caso de Bolivia.

Año IV, N? 15, p. 84 (octubre-diciembre 1970).

\section{LAFER, Celso}

Una redefinición del orden mundial y la Alianza Latinoamericana. Perspectivas y posibilidades.

Año VIII, No 31, p. 42 (julio-septicmbre 1975).

LOWENTHAL, Richard

Alemania y el fin del sistema bipolar en la política internacional.

No 3 y 4, p. 411 (octubre 1967-marzo 1968).

LUNA, Julio

El desarrollo pesquero y la integración regional.

Año IV, No 14, p. 183 (julio-septiembre 1970).

MARTINS, Luciano

Mayo de 1968: una revolución nueva e intransitiva.

Año III, No 10, p. 158 (julio-septicmbre 1969).

MATTELART, Armand

La dependencia de los medios de comunicación de masas en Chile.

Año IV, No 13, p. 124 (abril-junio 1970).

MAYOBRE, Eduardo, HURTADO, 
Héctor y PAZOS, Javier

El Caribe y Venezuela: integración de la integración.

Año VII, № 27, p. 3 (julio-septicmbre 1974).

MERLINI, Cesare

La posición internacional de Italia. Oportunidades y tentaciones.

Año V, $\mathrm{N}^{\circ} 17$, p. 76 (encro-marzo 1972).

MIHALY, Eugene B.

La estrategia de los Estados Unidos en el Pacífico Occidental y el dilema de Micronesia.

Año V, No 17, p. 25 (encro-marzo 1972).

MILLAR, T. B.

Los Océanos Indico y Pacífico: Algunas consideraciones estratégicas.

No 11, p. 321 (octubre-dicicmbre 1969).

MIRSKI, Gucorgui

El papel politico del ejército en los países de Asia y Africa.

Año IV, No 13, p. 3 (abril-junio 1970).

MONETA, Juan Carlos

Argentina y Australia: Esquemas para la cooperación.

Año VI, No 21, p. 55 (enero-marzo 1973).

Africa y los grandes actores externos.

Año VII, No 27, p. 31 (julio-septicmbre 1974).

MORAN, Theodore $\mathbf{H}$.

Nuevo trato a las materias primas. Año V, № 19, p. 56 (julio-septicmbre 1972).

MUNOZ, Heraldo y SANCHEZ, Walter.

La Détente y el Sistema Internacional.

Año VIII, No 32, p. 103 (octubrediciembre 1975).

MURPHY, Cornelius F. Jr.

Coacción económica y tratados desiguales.

Año IV, No 14, p. 82 (julio-septicmbre 1970).

NAUDON, Carlos

Cinco libros sobre Israel.

Año II, Ne 6, p. 271 (julio-scptiembre 1968).

NIEKERK, Arnold Van

La pendiente de la dependencia: una visión desde afuera.

Año V, No 18, p. 29 (abril-junio 1972).

América Latina y las Antillas Necrlandesas.

Año VI, No 23, p. 93 (julio-septiembre 1973).

OGELSBY, J. C. M.

Relaciones canadicnse - latinoamericanas, pasadas, presentes y futuras.

$\Lambda$ ño V, No 18, p. 68 (abril-junio 1972).

OLDFELT, Carin

Estudio comparativo sobre zonas pesqueras en el mundo.

Año 1V, No 13, p. 21 (abril-junio 1970).

ORREGO, Francisco

Dilema en el Grupo Andino.

No 11, p. 352 (octubre-diciembre 1969).

ORREGO VICUNA, Francisco

Algunos problemas de derecho internacional planteados por la nacionalización de la industria del cobre en Chile.

Año VI, No 24, p. 66 (octubre-diciembre 1973).

De la crisis de la energía al concepto del patrimonio económico de la humanidad: criterios para reestruc. turar cl sistema económico inter. nacional.

Año VIII, No 32, p. 3 (octubre-diciembre 1975).

ORTI7, Eduardo

Las grandes potencias y la crisis de Nigeria.

Año III, No 9, p. 352 (abril-junio 1969).

PALMA, Pclro A.

Análisis del Sistema Monetario Internacional.

Año VIII, NQ 32, p. 51 (octubre-diciembre 1975).

PALMA VICUNA, Ignacio

$\Lambda$ portes para un análisis de la crisis chilena.

Año VII, No 26, p. 39 (abril-junio 1974).

PAZOS, Javicr, HURTADO, Héctor y

MAYOBRE, Eduardo

El Caribe y Venezuela: integración de la integración. 
Año VII, No 27, p. 3 (julio-septiembre 1974).

PENAA, Félix

El Grupo Andino: un nuevo enfoque de la participación internacional de los países en desarrollo.

Año VI, N\$ 22, p. 44 (abril-junio 1973).

Tendencias y perspectivas de la in. tegración económica en América Latina,

Año VIII, No 29, p. 137 (enero-marzo 1975).

PEREL LLANA, Carlos E.

América Latina y los países no alineados.

Año VI, No 24, p. 43 (octubre-diciembre 1973).

¿l'otencias intermedias o países mayores? La política exterior de Argentina, Brasil y México.

$\Lambda$ ño VIII, No 29, p. 47 (encro-marzo 1975).

PETRAS, James y RIMENSNYDER,

Nelson

Los militares y la modernización del Perú.

Año IV, No 13, p. 90 (abril-junio 1970).

PETRAS, James

Venezuela: una década de democracia capitalista.

Año IV, No 15, p. 42 (octubre-diciembre 1970).

PINTOO, Aníbal

Relacioncs cconómicas entre América Latina y Estados Unidos: implicaciones y perspectivas políticas.

Año VI, No 22, p. 3 (abril-junio 1973).

RIBEIRO, Darcy

El desafío de la marginalidad.

Año IV, No 16, p. 93 (enero-marzo 1971).

Nucvos caminos de la Revolución Latinoamericana.

Año V, No 18, p. 3 (abril-junio 1972).

SABATO, Jorge A.

Encrgia atómica en Argentina.

Año II, No 7, p. 332 (octubre-diciembre 1968).

SACHS, Ignacy

Ecodesarrollo: un aporte a la definición de estilos de desarrollo pa- ra América Latina.

Año VII, No 25, p. 57 (enero-marzo 1974).

SAGASTI, Francisco y GUERRERO, Mauricio.

Situación de la ciencia y tecnología en América Latina.

Año VII, No 25, p. 16 (enero-marzo 1974).

SANCHEZ, Walter y MUÑOZ, Heraldo

La Détente y el Sistema Internacional.

Año VIII, No 32, p. 103 (octubrediciembre 1975).

SATHYAMURTHY, T. V.

Las relacioncs internacionales asiáticas: perspectivas contcmporáneas.

Año IV, $\mathrm{N}^{\circ} 15$, p. 3 (octubre-diciembre 1970).

SCHMITTER, Philippe C.

La portugalización de Brasil.

Año V, No 19, p. 3 (julio-septicmbre 1972).

SEPULVEDA, Alberto

El militarismo desarrollista en América Latina.

Año IV, No 15, p. 97 (octubre-diciembre 1970).

SIGMUND, Paul E.

El bloqueo invisible $y$ la caida de Allende.

Año VII, No 26, p. 20 (abril-junio 1974).

SILVA CASTRO, Raúl

Juan Egaña, precursor dc la integración latinoamcricana.

Año II, No 7, p. 387 (octubre-dicicmbre 1968).

SILVA MICHELENA, Josć $\Lambda$.

Tendencias recientes en la política mundial.

Año VI, No 23, p. 3 (julio-scptiembre 1973).

SNOW, Peter G.

Desarrollo ccon $6 \mathrm{mico}$ y Seguridad Nacional en el Régimen Militar Argentino.

Año V, No 20, p. 75 (octubre-diciembre 1972).

SUNKEL, Osvaldo

Política Nacional de desarrollo y dependencia externa.

Año I, No 1, p. 43 (abril 1967).

La tarea política y teórica del pla- 
nificador en América Latina.

Año II, No 8, p. 519 (cnero-marzo 1969).

Esperando a Godot: América Latina antc la nucva administración republicana de los Estados Unidos.

Año III, No 9, p. 23 (abril-junio 1969).

La Universidad Latinoamcricana ante el avance cicntífico y técnico; algunas reflexiones.

Año IV, Ne 13, p. 60 (abril-junio 1970).

Capitalismo transnacional y desintegración nacional en América Latina.

Año IV, No 16, p. 93 (encro-marzo 1971).

TADIC, Bojana

No-alincación; un vistazo histórico y conceptual.

Año III, Ne 10, p. 124 (julio-septiembre 1969).

TEITELBOIM, Sergio

Los paises del Pacífico Sur y el mar territorial.

Año IV, No 13, p. 38 (abril-junio 1970).

THOMAS, Hugh

La Revolución Cubana y sus raices históricas.

Año IV, No 16, p. 126 (enero-marzo 1971).

THOMSON, James C. Jr.

Vietnam: un caso clinico.

Año II, No 7, p. 317 (octubre-dicicmbre 1968).

TOMASSINI, Luciano

La misión imposible del presidente Nixon.

No 12, p. 512 (enero-marzo 1970).

Implicaciones internacionales del deterioro ecológico.

Año V, Ne 18, p. 88 (abril-junio 1972).

Tendencias favorables o adversas a la formación de un sistema regional latinoamericano.

Año VIII, No 29, p. 3 (cnero-marzo 1975).

TORRES-RIVAS, Edelberto

Desarrollo, integración y dependencia en Centroamérica.

No 12, p. 489 (enero-marzo 1970).

TOYNBEE, Amold
El estudio de la historia contemporánea.

Año I, Ne 1, p. 8 (abril 1967).

VELIZ, Claudio

El Instituto de Estudios Internacionales.

Año I, No 1, p. 3 (abril 1967).

Centralismo, Nacionalismo e Intcgración.

Año III, No 9, p. 3 (abril-junio $1969)$.

Cambio y continuidad: El Pacto An(lino en la historia contemporánca.

Año IV, No 16, p. 62 (enero-marzo 1971).

VERNANT, Jacques

El mundo, Europa y Francia.

No 2, p. 123 (julio 1967).

VILAS, Carlos María y $\Lambda \operatorname{COST} \Lambda$, Mer-

cedes

Santo Domingo y Checoslovaquia en la política de bloques.

Ano II, No 8, p. 565 (encro-marzo $1969)$.

VILI.ALBA VERA, Jovito A., CLAVERIE RODRIGUEZ, Heliodoro L.

y F.CHEVERRIA, Pedro Luis

El Tratado modificado de reciprociclat comercial entre Venezuela y los Estados Unidos.

Año V, No 19, p. 91 (julio-scpticmbre 1972).

VILLAGRAN KRAMER, Francisco

Mecanismos de regulación internacional de productos básicos.

Año VI, No 23, p. 61 (julio-septicmbre 1973).

WALLIS, Victor

La experiencia de Brasil con una politica exterior independiente.

An̆e I, No 2, p. 189 (julio 1967). WATKINS, Melville $\mathrm{H}$.

Canadá: industria y propiedad extranjera.

Año III, No 10, p. 144 (julio-septicmbre 1969).

WERTHEIM, W. F.

Indonesia antes y después del golpe dc Untung.

No 3 y 4 , p. 337 (octubre 1967marzo 1968).

YOUNGER, Kenneth

El papel de Gran Bretaña en la politica internacional.

No 2, p. 137 (julio 1967). 


\section{INDICE TEMATICO}

\section{TEMAS HISTORICOS}

\section{ABERASTURY, Marcelo}

Asia Oriental y Meridional y el Pacifico: Inicios de 1972.

Año V, No 17, p. 3 (enero-marzo 1972).

HOFFMANN, Stanley

El estilo norteamericano, su pasado, sus principios.

Año III, No 9, p. 48 (abril-junio 1969).

SILVA CASTRO, Raúl

Juan Egaña, precursor de la intcgración latinoamericana.

Año II, N? 7, p. 387 (octubre-diciembre 1968).

TADIC, Bojana

No alineación; un vistazo histórico y conceptual.

Año III, No 10, p. 124 (julio-septiembre 1969).

THOMAS, Hugh

La Revolución Cubana y sus raíces históricas.

Año VI, No 16, p. 126 (cnero-marzo 1971).

TOYNBEE, Arnold

El estudio de la historia contemporánea.

Año I, No 1, p. 8 (abril 1967).

VELIZ, Claudio

Centralismo, Nacionalismo e Intcgración.

Año III, No 9, p. 3 (abril-junio 1969).

Cambio y continuidad: El Pacto $\mathrm{An}$ dino en la historia contemporánea.

Año IV, No 16, p. 62 (enero-marzo 1971).

\section{POLITICA MUNDIAL}

ARAUjo CASTRO, J. A. de

El Continente Americano dentro de la problemática mundial.

Año V, N²0, p. 3 (octubre dicicmbre 1972).

CONSTANTINESCO, Leontin

Las relaciones Estados Unidos-Comunidad Económica Europea en la perspectiva de la Rueda Nixon.

Año VI, No 21, p. 44 (enero-marzo 1973).

GODOY, Horacio $\mathbf{H}$.

Los Acucrdos entre Ios Estados Unidos y la Unión de las Repúblicas Socialistas Soviéticas.

Año VII, No 28, p. 3 (octubre-diciembre 1974).

GOTT, Richard

El sur de Africa y el fin de la guerra fría.

Año I, Nọ 1, p. 95 (abril 1967).

HOLBRAAD, Carsten

El papel de las potencias medias en la política internacional.

Año V, No 17, p. 58 (enero-marzo 1972).

LOWENTHAL, Richard

Alemania y el fin del sistema bipolar cn la politica internacional.

No 3 y 1, p. 411 (octubre 1967-marzo 1968).

MONETA, Carlos J.

Africa y los grandes actores externos.

Año VII, No 27, p. 31 (julio-septiembre 1974).

MUNOZ, Heraldo y SANCHEZ, Walter

La Détente y el Sistema Internacional.

Año VIII, No 32, p. 103 (octubre-diciembre 1975).

NAUDON, Carlos

Cinco libros sobre Israel.

Año II, No 6, p. 271 (julio-septicmbre 1968).

PEREZ LLANA, Carlos E.

América Latina y los países no alineados.

Año VI, No 24, p. 43 (octubre-diciembre 1973).

SANCHEZ, Walter y MUNOZ, Heraldo

La Détente y cl Sistema Internacional.

Año VIII, NQ 32, p. 103 (octubrediciembre 1975).

SILVA MICHELENA, José A.

Tendencias recientes en la política mundial. 
$\Lambda$ ño VI, Ne 23, p. 3 (julio-septiem. bre 1973).

TOMASSINI, Luciano

La misión imposible del presidente Nixon.

№ 12 , p. 512 (enero-marzo 1970).

VERNANT, Jacques

E1 mundo, Europa y Francia.

Año I, No 2, p. 123 (julio 1967).

\section{TERCER MUNDO}

BURTON J. W.

No-alincación y política mundial contemporánca.

Año III, No 10, p. 107 (julio-septiembre 1969).

GOTT, Richard

E.l Congo a partir de Mobutu.

No 3 y 4, p. 443 (octubre 1967-marzo 1968).

MIHALY, Eugene B.

La estratcgia de los Estados Unidos en el Pacífico Occidental y el dilema de Micronesia.

Año V, No 17, p. 25 (enero-marzo 1972).

MILLAR, T. B.

Los Océanos Indico y Pacifico: Algunas consideraciones estratćgicas.

No 11, p. 321 (octubre-diciembre 1969).

MONETA, Carlos J.

Africa y los grandes actores externos.

An̄o VII, No 27, p. 31 (julio-septiembre 1974).

ORTI7, Eduardo

Las grandes potencias y la crisis de Nigeria.

Año III, No 9, p. 352 (abril-junio 1969).

SAIHYAMURTHY, T. V.

Las relaciones internacionales asiáticas: perspectivas contemporáneas.

Año IV, No 15, p. 3 (octubre-diciembre 1970).

WERTHEIM, W. F.

Indonesia antes y después del golpe de Untung.

No 3 y 4, p. 337 (octubre 1967-marzo 1968).

\section{POLITICA EXTERIOR}

END, Heinrich
La política exterior del gobierno Kiesinger-Brandt.

Año II, No 7, p. 358 (octubre-diciembre 1968).

GITHINGS, John

¿Tiene China una politica exterior? No 1, p. 76 (abril 1967).

JAGUARIBF, Helio

El Brasil y la América Latina.

Año VIII, No 29, p. 106 (enero-marzo $1975)$.

KAISER, Kar!

Una nueva política oriental en Alemania.

Año 1I, No 8, p. 543 (encro-marzo 1969).

MERLINI, Cesare

La posición internacional de Italia. Oportunidacles y tentaciones.

Año V, No 17, p. 76 (encro-marzo 1972).

MONETA, Juan Carlos

Argentina y Australia: Esquemas pa. ra la cooperación.

Año VI, No 21, p. 55 (encro-marzo 1973).

PEREZ LLANA, Carlos

¿Potencias intermedias o paises mayores? La política exterior de Argentina, Brasil y México.

Año VIII, No 29, p. 47 (enero-marzo 1975).

TOMASSINI, Luciano

Tendencias favorables o adversas a la formación de un sistema regional Iatinoamericano.

Año VIII, No 29 , p. 3 (encro-marzo 1975).

W.ILLIS, Victor

Ia cxperiencia de Brasil con una política exterior independiente.

Año I, No 2, p. 189 (julio 1967).

YOUNGER, Kenneth

El papel de Gran Bretaña en la política internacional.

No 2, p. 137 (julio 1967).

\section{ASUNTOS POLITICOS}

BERNSTEIN, Enrique

Situación politica en vispera de ma. yo de 1968.

Año V, No 19, p. 103 (julio-septiembre 1972). 


\section{BODENHEIMER, Susanne}

La crisis del movimiento socialdemócrata en América Latina.

No 12, p. 544 (encro-marzo 1970).

CIRIA, Alberto

La comunicación política en Américat Latina: Algunos de sus probleinas.

Año 11. No 8, p. 530 (enero-marzo 1969).

CLARKSON, Stephen

Ia int:-lligentsia satélite: los intelectuales canadienses frente a los Estaclos linidos.

Año V, N? 18, p. 41 (abril-junio $1972)$.

JAGLARIBE, Helio

Los acontecimientos chilenos.

Año VII, No 26, p. 3 (abril-junio 1974).

M.IIIEL.IRT, Armand

La dependencia de los medios de commnicación de masas en Chile.

Año IV, No 13, p. 124 (abril-junio I!)7(0).

PAIAMA VICUNAA, Ignacio

Aportes para un analisis de la crisis chilena.

Año VII, No 26, p. 39 (abril-junio 1974).

PETRAS, James

Vencencla: una década de democracia capitalista.

Año IV, No 15 , p. 12 (octubre-diciembre 1970).

SIGMUND, Paul E.

El bloqueo invisible y la caida de Allende.

Año V11, No 26, p. 20 (abril-junio $1974)$.

\section{ASUNTOS ESTRATEGICOS \\ $Y$ MILITARES}

C.ADENA, Cecilia y JOXE, Alain

Arnamentismo dependiente: Caso Latinoamericano.

Año IV, Ne 14, p. 3 (julio-scpticmbre 1970).

FAUNDEZ, Julio

El presidente de Estados Unidos y la facultad para hacer la guerra. Año IV, No 15, p. 60 (octubre-diciembre 1970).
JAGUARIDE, Helio

El Victnam y los Estados Unidos.

Año VIII, No 31, p. 3 (julio-septiembre 1975).

JOXE, Mlain

Hacia una nucva concepción de la scguridad curopea.

Año I, No 2, p. 156 (junio 1967).

Cohetes anticohetes: ¿Regreso a estrategias defensivas?

Año II, Nơ 5, p. 115 (abril-junio 1969).

Doctrina cstratégica y gucrras de intervención.

Año II, No 6, p. 276 (julio-septiembre 1968).

JOXE, Alain y CADENA, Cecilia

Armamentismo dependiente: Caso Latinoamericano.

Año IV, No 14, p. 3 (julio-septiembre 1970).

\section{CONFLICTOS INTERNACIONALES}

DEVILLERS, Philippc

Francia y la Segunda Guerra del Vietnam.

Año II, No 6, p. 214 (julio-septicmbre 1968).

GIT'TINGS, John

Ultimos libros sobre la guerra en Vietnam.

No 2, p. 212 (julio 1967).

La nueva guerra en Indochina.

Año IV, No 14, p. 104 (julio-septiembre 1970).

JAGUARIBE, Helio

El Victnam y los Estados Unidos.

Año VIII, N? 31, p. 3 (julio-septiembre 1975).

SIGMUND, Paul E.

El bloquco invisible y la caida de Allende.

Año VII, No 26, p. 20 (abril-junio 1974).

THOMSON, James C. Jr.

Vietnam: un caso clínico.

Año 11, No 7, p. 317 (octubre-dicicmbre 1968).

PAPEL DE LAS FUERZAS

ARMADAS

GITTINGS, John 
El Ejército Popular de Liberación y la Revolución Cultural.

Año II, N2 5. p. 3 (abril-junio 1968). MIRSKI, Gueorgui

El papel político del ejército en los paises de Asia y Africa.

$\Lambda$ ño IV, No 13, p. 3 (abril-junio 1970).

PETRAS, James y RIMFNSNYDER,

Nelson

Los militares y la modernización del I'erú.

Año IV, N? 19, p. 90 (abril-junio 1970).

RIMENSNYIER, Nelson y I'ETRAS, James

Los militares y la modernización del Perí.

Año IV, N» 13, p. 90 (abril-junio 1970).

SEPULVEDA, Alberto

E.l militarismo desarrollista en América Latina.

Año IV. N? 15, p. 97 (octubre-di. ciembre 1970).

SNOW, Peter G.

Desarrollo cconómico y Seguridad Nacional en el Régimen Militar Irgentino.

Año V, No 20, p. 67 (octubre-diciembre 1972).

\section{SUBVERSION Y SEGLRIDAD}

ALMEYDA, Cloclomiro

La OLAS y la Crisis Politica de América Latina.

No 3 y 4, p. 427 (octubre 1967marzo 1968).

FAUNDF7, Julio

El Sistema Interamericano de Seguridad en la política exterior de Estados Unidos.

No 11, p. 372 (octubre-diciembre 1969).

GOTT, Richard

La experiencia guerrillera en Bolivia.

Año II, No 5, p, 85 (abril-junio 1968).

JOXE, Alain

Doctrina estratégica y guerras de intervención.

Año 1I, No 6, p. 276 (julio-septiembre 1968).

¿Fin de la preponderancia estratégica norteamericana?
No 1I, p. 273 (octubre-diciembre 1968).

\section{DISARROLLO ECONOMICO}

B.ILTR.A, Alberto

América Latima y la Segunda UNC. TAD.

Año II, No 8, p. 419 (enero-marzo 1969).

CRONER, Claos

Estudio solure el subdesarrollo colombiano. Comentario crítico.

Nno IV, No 14, p. 117 (julio-septiembre 1970).

G.ARCIA, Antonio

proceso $y$ frustración de las Reformas Agrarias en América Latina.

No 3 y 4,1 , 353 (octubre 1967-marzo 1968).

HIRSCHMAN, Alluert O.

Liderazgo, percepción del cambio y stubdesarrollo.

Año II, N" 6, p. 258 (julio-septiembre 1968).

K.:D:IR, Bela

Los paises pequeños en la cconomía mundial.

Iño IV, No 16, p. 158 (encro-marzo 1971).

KALECKI, M. y KULA, Marcin

Notas solure los aspectos sociales y económicos de los "Regímenes Intermeclios"; el caso de Bolivia.

Sino IV, No 15, P. 84 (octubre-ticiembre 1970).

KI'LA, Marcin y KALECKI, M.

Notas sobre los aspectos sociales y cconómicos de los "Regímenes Internedios"; el caso de Bolivia.

Año IV, No 15, p. 84 (octul)rediciembre 1970).

RIBEIRO, Darcy

El desafio de la marginalidad.

Iño IV, No li. p. 93 (cnero-marzo 1971).

S.AC.HS, Ignacy

Ecodesarrollo: un aporte a la definición de estilos de desarrollo para América latina.

Iño VII, No 25, p. 57 (cnero-marzo 1971).

SUINKEL, Osvaldo 


\section{ESTUDIOS INTERNACIONALES}

La tarea política y teórica del planificador en América Latina.

Año II. No 8, p. 519 (enero-marzo 1969).

\section{DESARROLLO TECNOLOGICO Y ECOLOGIA}

\section{BULL, Hedley}

Las Relaciones Internacionales como ocupación académica.

Año VII, No 28, p. 76 (octubre-diciembre 1974).

GUERRERO, Mauricio y SAGASTI, Francisco

Situación de la ciencia y tecnología en América Latina.

Año VII, N9 25, p. 16 (enero-marzo 1974).

HALTY CARRERE, Máximo

¿Hacia un nucvo orden tecnológico?

Año VIII, No $32, \mathrm{p}, 33$ (octubre-diciembre 1975).

HERRERA, Amilcar O.

La ciencia en el desarrollo de América Latina.

Año II, No 5, p. 38 (abril-junio 1968).

HERRERA, Felipe

América Latina y el desafío internacional para la educación.

Año VII, No 25, p. 3 (enero-marzo 1974).

JAGUARIBE, Helio

El equilibrio ccológico mundial y los paises suhdesarrollados.

Año V, No 17. p, 92 (cnero-marzo 1972).

LUNA, Julio

El desarrollo pesquero y la integración regional.

Ano IV, Ne 14, p, 133 (julio-septicmbre 1970).

SABATO, Jorge A.

Encrgía atómica en Argentina.

Año II, No 7, p. 332 (octubre-dicicm. bre 1968).

S.ACHS, Ignacy

Ecodesarrollo: un aporte a la definición de estilos de desarrollo para América Latina.

Anio VII, No 25, p. 57 (enero-marzo 1974).

SAGASTI, Francisco $y$ GUERRERO,

Mauricio

Situación de la ciencia y tecnologia cn América Latina.

Año VII, No 25, p. 16 (enero-marzo 1974).

SLINKEL, Osvaldo

La Universidad Latinoamericana ante el avance cientifico y técnico: algunas reflexiones.

Año IV, No 13, p. 60 (abril-junio 1972).

TOM.ASSINI, Luciano

Implicaciones internacionales del deterioro ecológico.

Año V, No 18, p. 88 (abril-junio 1972).

\section{RECURSOS NATURALES \\ Y PRODUCTOS BASICOS}

\section{$\triangle Z I Z$, Sartaj}

Los verdaderos problemas de la crisis de alimentos.

Año VIII, Ne 30, p. 119 (abril-junio 1975).

BY"TH, James

Niugini: una nueva nación cuprífera en el Pacífico sc acerca a su independencia.

Año VI, No 22, p. 82 (abril-junio 1973).

CLAVERIE RODRIGUEZ, Heliodoro

L., ECHEVERRIA, Pedro Luis y VI-

LLALBA VERA, Jovito A.

E. Tratado modificado de reciprocidad comercial entre Venezuela y los Estados Unidos.

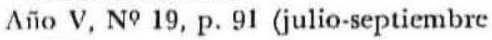
1972).

GIRVAN, Norman

F1 conflicto de Guyana - ALCAN y la nacionalización de DEMBA.

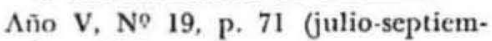
bre 1972).

GRANT, Jamcs P.

Las naciones de la OPEP: ¿Asociados o competidores:

Año VIII, No 30, p. 100 (abril-junio 1975)

LUNA, Julio

El desarrollo pesquero y la integración regional

Año IV, No 14, p. 133 (julio-septiembre 1970)

MORAN, Theodore $\mathrm{H}$.

Nuevo trato a las materias primas. 
Año V, No 19 , p. 56 (julio-septicmbre 1972).

OLDFELT, Carin

Estudio comparativo sobre zonas pesqueras en el mundo.

Año IV, No 13, p. 21 (abril-junio 1970).

ORREGO VICUNA, Francisco

Algunos problemas de derecho internacional planteados por la nacionalización de la industria del cobre en Chile.

Año VI, N? 24, p. 66 (octubre-diciembre 1973).

SABATO, Jorge A.

Energía atómica en Argentina.

Año II, No 7, p. 332 (octubre-diciembre 1968).

TEITELBOIM, Sergio

Los países del Pacífico Sur y el mar territorial.

Año IV, Ne 13, p. 38 (abril-junio 1970).

VILLAGRAN KRAMER, Francisco

Mecanismos de regulación internacional de productos básicos.

Año VI, No 23, p. 61 (julio-septiem. bre 1973).

\section{IMPERIALISMO Y DEPENDENCIA}

ACOSTA, Merecdes y VILAS, Carlos María

Santo Domingo y Checoslovaquia en la política de bloques.

Año II, No 8, p. 565 (enero-marzo 1969).

CI.AVERIE RODRIGUEZ, Hcliodoro

L., ECHEVERRIA, Pedro Luis y VI.

LLALBA VERA, Jovito A.

El Tratado modificado de reciprocidad comercial entre Venezucla y los Estados Unidos.

Año V, No 19, p. 91 (julio-septiembre 1972).

FURTADO, Celso

La concentración del pợer económico en los Estados Unidos y sus proyecciones en América Latina.

No 3 y 4, p. 323 (octubre 1967-marzo 1968).

GIRVAN, Norman

Teorias de dependencia económica en cl Caribe y Latinoamérica: un es- tudio comparativo.

Año VI, No 23, p. 61 (julio-septicmbre 1973).

I.M. W., José Luis de

¿Adiós a la tcoría de la dependencia? Una perspectiva desde la Argentina.

Año VII, No 28, p. 49 (octubre-diciembre 1974).

JOXE, Alain

Doctrina estratégica y guerras de intervención.

Año II, No 6, p. 276 (julio-septiembre 1968).

JOXE, Alain y CADENA, Cecilia

Armamentismo dependiente: Caso Latinoamericano.

Año IV, No 14, p. 3 (julio-septiembre 1970).

MIURPHY, Cornclius F. Jr.

Coacción económica y tratados desiguales.

Año IV, N゚ 14, p. 82 (julio-septiembre 1970).

NIEKERK, Arnold Van

La pendiente de la dependencia: una visión desde afucra.

Año V, N\& 18, p. 29 (abril-junio 1972).

PENA, Félix

F.l Grupo Andino: un nucvo enfoque de la participación internacional de los paises en desarrollo.

Anio VI, No 22, p. 44 (abril-junio 1973).

SUNKEL, Osvaldo

Politica Nacional de desarrollo y dependencia externa.

Año I, No 1, p. 43 (abril 1967).

Esperando a Godot: América Latina ante la nueva administración republicana de los Estados Unidos.

Año III, No 9, p. 23 (abril-junio 1969).

Capitalismo transnacional y desintegración nacional en $\Lambda$ mérica Latina.

Año IV, No I6, p. 93 (enero-marzo 1971).

Relaciones económicas entre América Latina y Estados Unidos . Comentarios al trabajo de Aníbal Pinto.

Año VI, No 22, p. 32 (abril-junio 1973).

TOMASSINI, Luciano 
La misión imposible del presidente Nixon.

No 12, p. 512 (encro-marzo 1970).

VILAS, Carlos María y ACOSTA, Mercedes

Santo Domingo y Checoslovaquia en la politica de bloques.

Año 1I, No 8, p. 565 (encro-marzo 1969).

\section{CORPORACIONES}

MULIIINACIONALES

FOGARTY, John

Australia y el problema de las inversiones extranjeras.

Año VI, No 22, p. 106 (abril-junio 1973).

FURTADO, Celso

La concentración del poder económico en los Estados Unidos y sus proyecciones en América Latina.

No 3 y 4, p. 323 (octubre 1967-marzo 1968).

GIRVAN, Norman

EI conflicto de Guyana - ELCAN y la nacionalización de DEMBA.

Año V. No 19, p. 71 (julio-septiembre 1979 ).

SUNKEL, Osvaldo

Capitalismo transnacional y desintegración nacional en América Latina.

Año IV, No 16, p. 93 (encro-marzo 1971).

WATKINS, Melville $H$.

Canatlá: industria y propicdad extranjera.

Año III. No 10, p. 144 (julio-septicubre 1969).

\section{INTEGRICION ECONOMICA}

\section{BERGSTEN, C. Fred}

Relaciones cconómicas entre Estados Lnidos y Latinoamérica: la estructura internacional y algunos enfoques posibles.

Año VIII, No 31, p. 19 (julio-septiembre 1975).

DIA7. ALEJANDRO, Carlos F.

El Grupo Andino en el proceso de Integración Latinoamericana.

Año II, No 6, p. 242 (julio-scpticmbre 1968).
FERRER, Aldo

Relaciones económicas entre la Comunidad Económica Europea y América Latina.

Año VI, No 24, p. 3 (octubre-diciembre 1973).

FRONDIZI, Arturo

El problema nacional de América Latina y ciertos esquemas de integración regional.

No 3 y 4, p. 285 (octubre 1967-marzo 1968).

GODOY, Horacio H.

La integración de América Latina y el proceso del poder mundial.

Año II, No 7, p. 368 (octubre-diciembre 1968).

HANSEN, Roger

Relaciones económicas cntrc los Estados Unidos y América Latina. Bilaterales, regionales o globales?

Año VIII, No 31, p. 59 (julio-septicmbre 1975).

HLRRERA, Felipe

Viabilidacl de una comunidad latinoamericana.

Año I, No 1, p. 21 (abril 1967).

La tarea inconclusa: América Latina integrada.

Año VI, No 21, p. 3 (encro-marzo 1973).

HURTADO, Héctor, MAYOBRE,

Eduardo y PAZOS, Javier

El Caribe y Venezuela: integración de la integración.

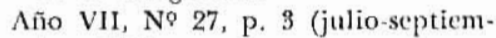
bre 1974).

KOJIMA, Kiyoshi

Un área de libre comercio del Pacifico.

Año V, No 20, p. 53 (octubre-diciembre 1972).

LAFER, Celso

Una redefinición del orden mundial y la Alianza Latinoamericana. Perspectivas y posibilidades.

Año VIII, N? 31, p. 42 (julio-septicmbre 1975).

MAYOBRE, Eduardo, HURTADO,

Héctor y PAZOS, Javier

El Caribe y Venezuela: integración de la integración.

Año VII, No 27, p. 3 (julio-septiembre 1974). 
ORREGO, Francisco

Dilemas en el Grupo Andino.

No 11, p. 352 (octubre-diciembre 1969).

PAZOS, Javier, HURTADO, Héctor y

MAYOBRE, Eduardo

El Caribe y Venezuela: integración de la integración.

Año VII, No 27, p. 3 (julio-septiembre 1974).

PENAA, Félix

Tendencias y perspectivas de la integración económica en América Latina.

Año VIII, No 29, p. 137 (enero-marzo 1975).

TORRES-RIVAS, Edelberto

Desarrollo, integración y dependencia en Centroamérica.

№ 12, p. 489 (enero-marzo 1970).

VELIZ, Claudio

Cambio y continuidad: El Pacto Andino en la historia contemporánea.

Año IV, No 16, p. 62 (enero-marzo 197I).

\section{ECONOMIA INTERNACIONAL}

BERGSTEN, C. Fred

Rclacioncs cconómicas entre Estados Unidos y Latinoamérica: la cstructura internacional y algunos enfoques posibles.

Año VIII, No 31, p. 19 (julio-scptiembre 1975).

FERRER, Aldo

La crisis del sistema monetario internacional. Un enfoquc estructuralista.

Año VIII, No 30, p. 48 (abril-junio 1975).

FURTADO, Celso

Una interpretación estructuralista de la "crisis" actual del capitalismo.

Año VIII, No 30, p. 3 (abril-junio 1975).

HODAR.A, Joseph

La estructura internacional: cuatro versiones.

Año VIII, No 31, p. 100 (julio-septiembre 1975).

ORREGO VICUNA, Francisco

De la crisis de la encrgía al concepto del patrimonio económico de la humanidad: criterios para recstructurar el sistema económico internacional.

Año VIII, No 32, p. 3 (octubre-diciembre 1975).

PALMA, Pedro A.

Análisis del Sistema Monetario Internacional.

Año VIII, No 32, p. 51 (octubre-dicicmbre 1975).

\section{PROCESOS REVOLUCIONARIOS}

BERNSTEIN, Enrique

Situación política en vísperas de mayo de 1968.

Año V, No 19, p. 103 (julio-septiembre 1972).

COTLER, Julio

Crisis política y populismo militar en el Perú.

No 12, p. 439 (cnero-marzo 1970).

DELGADO, Carlos

Sobre algunos problemas de la participatción en la Revolución Pcruana.

Año VI, Ne 21, p. 24 (enero-marzo 1973).

GITTINGS, John

El Ejército Popular de Liberación y la Revolución Cultural.

Año II, No 5, p. 3 (abril-junio 1968).

IRELAND, Rowan

La Iglesia Católica del Brasil: límites del aggiornamento.

Año VII, No 27, p. 76 (julio-septiembre 1974).

MARTINS, Luciano

Mayo de 1968: una revolución nueva c intransitiva.

Año III, No 10, p. 158 (julio-scptiembre 1969).

RIBLIRO, Darcy

Nuevos caminos de la Revolución Latinoamericana.

Año V, No 18 , p. 3 (abril-junio 1972).

\section{PROBLEMAS DEL SOCIALISMO}

ACOSTA, Mercedes y VILAS, Carlos Maria

Santo Domingo y Checoslovaquia en la politica de bloques.

Año II, No 8, P. 565 (enero-marzo 1969). 
BAMBIRRA, Vania

La Revolución Cultural y el Marxismo.

Año II, No 7, p. 406 (octubre-diciembre 1968).

BOGNAR, Jozsef

Reforma económica en Hungría.

Año III, No 10, p. 107 (julio-septicmbre 1969).
GITTINGS, John

¿Tiene China una política exterior? No 1, p. 76 (abril 1967).

VILAS, Carlos María y ACOSTA, Mercedes

Santo Domingo y Checoslovaquia en la política de bloques.

Año II, No 8, p. 565 (enero-marzo 1969).

\section{INDICE GEOGRAFICO}

AMERICA LATINA cn general

ALMEYDA, Clodomiro

La OLAS y la crisis política de América Latina.

No 3 y 4, p. 427 (octubre 1967-marzo 1968).

ARAUjo CASTRO, L. A. de

El Continente Americano dentro de la problemática mundial.

Año $\mathrm{V}, \mathrm{N}$ 20, p. 3 (octubre-diciembre 1972).

B.ALTRA, Alberto

América Latina y la Segunda UNC. TAD.

Año II, No 8, p. 449 (enero-marzo 1969).

BERGSTEN, C. Fred

Relaciones económicas entre Estados Unidos y Latinoamérica: la estructura internacional y algunos enfoques posibles.

Año VIII, Ne 31, p. 19 (julio-septicmbre 1975).

BODENHEIMER, Susanne

La crisis del Movimiento Socialdemócrata en América Latina.

No 12, p. 544 (enero-marzo 1970).

CADENA, Cecilia y JOXE, Alain

Arnamentismo dependiente: Caso Latinoamcricano.

Año IV, No 14, p. 3. (julio-septiembre 1970).

CIRIA, Alberto

La comunicación política en América Latina: Algunos de sus problemas.

Año II, $\mathrm{N}^{\circ} 8$, p. 530 (enero-marzo 1969).

CRONER, Claos

Estudio sobre el subdesarrollo colom- biano. Comentario crítico.

Año IV, No 14, p. 117 (julio-septiembre 1970).

DELGADO, Carlos

Sobre algunos problemas de la participación en la Revolución Peruana.

Año VI, No 21, p. 24 (encro-marzo 1973).

FAUNDEZ, Julio

El sistema interamericano de seguridad en la política exterior de Estados Unidos.

No 11, p. 372 (octubre-diciembre 1969).

FERRER, Aldo

Relaciones económicas entre la Comu. nidad Económica Europea y América Latina.

Año VI, No 24, p. 3 (octubre-diciem. bre 1973).

FRONDIZI, Arturo

El problema nacional de América Latina y ciertos esquemas de integración regional.

No 3 y 4, p. 385 (octubre 1967-marzo 1968).

\section{FURTADO, Celso}

Lit concentración del poder económico en los Estados Unidos y sus proyecciones en América Latina.

No 3 y 4, p. 353 (octubre 1967-marzo 1968).

GARCIA, Antonio

Proceso y frustración de las Reformas Agrarias en América Latina.

No 3 y 4, p. 353 (octubre 1967-marzo 1968).

GIRVAN, Norman

El conflicto de Guyana - ALCAN y la nacionalización de DEMBA. 
Año V, No 19, p. 71 (julio-scptiembre 1972).

Teorías de dependencia económica en el Caribe y Latinoamérica: un estudio comparativo.

Año VI, Ne 23, p. 23 (julio-septiembre 1973).

GODOY, Horacio $\mathbf{H}$.

La integración de América Latina $y$ el proceso del poder mundial.

Año II, No 7, p. 868 (octubre-diciembre 1968).

GUERRERO, Mauricio y SAGASTI,

Francisco

Situación de la ciencia y tccnologia en Amética Latina.

Año VII, Ne 25, p. 16 (enero-marzo 1974).

HANSEN, Roger

Relaciones económicas entre los Estados Unidos y América Latina. ¿ $\mathrm{Bi}$ latcrales, regionales o globales?

Año VIII, No 31 , p. 59 (julio-septiembre 1975).

HERRERA, Amilcar O.

La ciencia en el desarrollo de Améríca Latina.

Año II, Ne 5, p. 38 (abril-junio 1968).

HERRERA, Felipe

Viabilidad de una comunidad latinoamcricana,

Año I, No 1, p. 21 (abril 1967).

La tarca inconclusa: América Latina integrada.

Año VI, No 21, p. 3 (enero-marzo 1973).

JAGUARIBE, Hclio

El Brasil y la América Latina.

Año VIII, No 29, p. 106 (enero-marzo 1975).

JOXE, Alain y CADENA, Cecilia

Armamentismo dependiente: Caso Latinoamericano.

Año IV, No 14, p. 3 (julio-scptiembre 1970).

LAFER, Celso

Una redefinición del orden mundial y la Alianza Latinoamericana. Perspectivas y posibilidades.

Año VIII, No 31, p. 42 (julio-septiembre 1975).

LUNA, Julio

El desarrollo pesquero y la integra- ción regional.

Año IV, No 14, p. 139 (julio-septiem. bre 1970).

MONETA, Juan Carlos

Argentina y Australia: Esquemas para la cooperación.

Año VI, No 21, p. 55 (encro-marzo 1973).

NIEKERK, Arnold E. Van

América Latina y las Antillas Neer landesas.

$\Lambda$ ño VI, No 23, p. 93 (julio-septiembre 1973).

PENA, Félix

Tendencias y perspectivas de la integración económica en América La. tina.

Año VIII, No 29, p. 137 (encro-marzo 1975).

PEREZ LLANA, Carlos

¿Potencias intermedias o paises mayores? La política exterior de Argentina, Brasil y México.

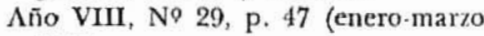
1975).

RIBEIRO, Darcy

Nuevos caminos de la Revolución Latinoamericana.

Año V, No 18, p. 3 (abril-junio 1972).

SACHS, Ignacy

Ecodesarrollo: un aporte a la definición de estilos de desarrollo para América Latina.

Año VII, No 25, p. 57 (cnero-marzo 1974).

SAGASTI, Francisco y GUERRERO,

Mauricio

Situación de la ciencia y tecnología en América Latina.

Año VII, No 25, p. 16 (enero.marzo 1974).

SEPULVEDA, Alberto

El militarismo desarrollista en Amé. rica Latina.

Año IV, No 15, p. 97 (octubre-diciembre 1970).

SUNKEL, Osvaldo

La tarea política y teórica del planificador en América Latina.

Año II, No 8, p. 519 (enero-marzo 1969).

Esperando a Godot: América Latina ante la nueva administración re. publicana de los Estados Unidos. 
Año III, Ne 9, p. 23 (abril-junio 1969).

La Universidad Latinoamericana ante cl avance cientifico y técnico: algunas reflexiones.

Año IV, No 13, p. 60 (abril-junio $1970)$.

Capitalismo transnacional y desintegración nacional en América Latina.

Año IV, No 16, p. 93 (encromarzo 1971).

Relaciones económicas entre América Latina y Estados Unidos - Comentarios al trabajo de Anibal Pinto.

Año V'I, Ne 22, p. 32 (abril-junio 1973).

TOMASSINI, Luciano

Tendencias favorables o adversas a la formación de un sistema regional latinoamericano.

Año VIII, No 29, p. 3 (enero-marzo 1975)

\section{AMERICA CENTRAL Y EL CARIBE}

ACOSIA, Mercedes y VILAS, Carlos Maria

Santo Domingo y Checoslovaquia en la política de bloques.

Aūo II, Ne 8, p. 565 (enero-marzo 1969).

GIRV.IN, Norman

Terias de dependencia económica en el Caribe y Latinoamérica: un estudio comparativo.

Año VI, No 23, p. 23 (julio-septiembre 1973).

HURTADO, Héctor, MAYOBRE,

Eduardo y PAZOS, Javier

El Caribe y Venczucla: integración clc la integración.

Año VII, No 27, p. 3 (julio-septicm. lire 1974).

MA YOBRE, Eduardo, HURTADO,

Héctor y PAZOS, Javier

El Caribe y Vencaucla: integración die la integración.

Año VII, No 27, ). 3 (julio-septicm bre 1974).

NIEKERK, Arnold E. Van

América Latina y las Antillas Neerlandesas.

Año VI, No 23, p. 93 (julio-septicm- bre 1973).

PAZOS, Javier, HURTADO, Héctor y

M.IYOBRE, Eduardo

El Caribe y Venezucla: integración de la integración.

Año VII, No 27, P. 3 (julio-septiembre 1974).

PENA, Félix

El Grupo Andino: un nuevo enfoque (le la participación internacional de los paises en desarrollo.

Año VI, No 22, p. 44 (abril-junio 197.3).

THOMAS, Hugh

La Revolución Cubana $y$ sus raíces históricas.

Año IV, No 16, p. 126 (cnero-marzo 1971).

TORRES-RIVAS, Edelberto

Desarrollo, integración y dependencia en Centroamérica.

No 12, p. 489 (encro-marzo 1970).

VILAS, Carlos María y ACOS'TA, Mercedes

Santo Domingo y Checoslovaquia en la politica de bloques.

Año 1I, No 8, p. 565 (enero-marzo $1969)$.

\section{AMERICA DEL SUR}

\section{GOTT, Richard}

La experiencia guerrillera en Bolivia.

Año II, No 5, p. 85 (alsril-junio 1968).

IMAZ, José Luis de

¿Adiós a la teoria de la dependencia? Una perspectiva desde la Argentina.

Año VII, No 28, p. 49 (octubre-diciembre 1974).

IRELAND, Rowan

La Iglesia Católica del Brasil: límites del aggiornamento.

Año VII, № 27, p. 76 (julio-septiembre 1974).

JAGUARIBE, Helio

Los acontecimicntos chilenos.

Año VII, No 26, p. 3 (abril-junio 1974).

El Brasil y la América Latina.

Año VIII, No 29, p. 106 (enero-marzo 1975).

KALECKI, M. y KULA, Marcin

Notas sobre los aspectos sociales y 
cconómicos de los "Regímencs In. termedios"; el caso de Bolivia.

$\Lambda$ ño IV, No 15, p. 84 (octubre-diciembre 1970).

KLLA, Marcin y KALECKI, M.

Notas sobre los aspectos sociales y económicos de los "Regimenes Intcrinedios"; el caso de Bolivia.

Año IV, No 15, p. 84 (octubre-dicicmbre 1970).

ORREGO VICUNA, Francisco

Algunos problemas de derccho internacional planteados por la nacionalización de la industria del cobre en Chilc.

Año VI, No 24, p. 66 (octubrediciembre 1973).

PALMA VICUNA, Ignacio

Aportes para un análisis de la crisis chilena.

Año VII, No 26, p. 39 (abril-junio $197.1)$.

PEREZ LLANA, Carlos

¿Potencias intermedias o paises mayores? La política exterior de Argentina, Brasil y México.

Año VIII, No 29, p. 47 (enero-marzo 1975).

SABALO, Jorge A.

Encrgia atómica en Argentina.

Año II, No 7, p. 90 (octubre-diciembre 1968).

SCHMIT TER, Philippe C.

La portugalización de Brasil.

An̆о V, Ne 19, p. 3 (julio-septicmbre 1972).

SIGMUND, Paul E.

El bloqueo invisible y la caida de Allende.

Año VII, Ne 26, p. 20 (abril-junio 1974).

SNOW, Peter G.

Desarrollo cconómico y Scguridad Nacional en el Régimen Militar Argentino.

Aกัo V, No 20, p. 67 (octubre-diciembre 1972).

WALLIS, Victor

La experiencia de Brasil con una politica exterior independiente.

Año I, Ne 2, p. 189 (julio 1967).

\section{GRUPO ANDINO}

CLAVERIE RODRIGUEZ, Heliodoro
L., ECHEVERriA, Pedro Luis y VI-

LLALBA VERA, Jovito A.

El Tratado modificado de reciprocidad comercial entre Venezuela y los Estados Unidos.

Año V, No 19, p. 91 (julio-septiembre 1972).

CLOTER, Julio

Crisis política y populismo militar en el Perú.

No 12, p. 439 (enero-marzo 1970).

DIAZ ALEJANDRO, Carlos F.

El Grupo Andino en el proceso de Integración Latinoamericana.

Año II, Ne 6, p. 242 (julio-septicmbre 1968).

DELGADO, Carlos

Sobre algunos problemas de la participación en la Revolución Peruana.

Año VI, Ne 2I, p. 24 (enero-marzo 1973).

ECHEVERRIA, Pedro Luis, CLAVE-

RIE RODRIGUEZ, Heliodoro L., VI-

LLALBA VERA, Jovito A.

El Tratado modificado de reciprocidad comercial entre Venezuela y los Estados Unidos.

Año V, No 19, p. 91 (julio-septicmbre 1972).

MATTELART, Armand

$\mathrm{La}$ dependencia de los medios de comunicación de masas en Chile.

Año IV, Ne 13, p. 124 (abril-junio 1970).

ORREGO, Francisco

Dilemas en el Grupo Andino.

No 11, p. 352 (octubre-diciembre 1969)

PENA, Félix

El Grupo Andino: un nucvo enfoque de la participación internacional de los paises en desarrollo.

Año VI, No 22, p. 44 (abril-junio 1973).

PETRAS, James y RIMENSNYDER, Nelson

Los militares y la modernización del Perú.

Año IV, No 13, p. 90 (abril-junio 1970).

PETRAS, James

Venezucla: una década de democracia capitalista.

Año IV, No 15, p. 42 (octubre-diciembre 1970). 
RIMENSNYDER, Nelson y PETRAS, James

Los militares y la modernización del Perú.

Año IV, No I3, p. 90 (abril-junio 1970).

VELIZ, Claudio

Cambio y continuidad: El Pacto Andino en la historia contemporánea.

Año IV, No 16, p. 62 (enero-marzo 1971).

VILLALBA VERA, Jovito A., CLAVERIE RODRIGUEZ, Hcliodoro L., ECHEVERRIA, Pedro Luis

El Tratado modificado de reciprocidad comercial entre Venezuela y los Estados Unidos.

Año V, No 19, p. 91 (julio-septiembre 1972).

\section{ESTADOS UNIDOS}

\section{BERGSTEN, C. Fred}

Relaciones económicas entre Estados Unidos y Latinoamérica: la cstructura internacional y algunos enfoques posibles.

Año VIII, No 31, p. 19 (julio-septiembre 1975).

\section{CLARKSON, Stephen}

La intelligentsia satćlite: los intelectuales canadienses frente a Ios Estados Unidos.

Año $V, N^{\circ} 18$, p. 41 (abril-junio 1972).

CLAVERIE RODRIGUEZ, Heliodoro L., ECHEVERRIA, Pedro Luis y VI-

LLALBA VERA, Jovito A.

E1 Tratado modificado de reciprocidad comercial entre Venezuela y los Estados Unidos.

$\Lambda$ ño V, No 19, p. 91 (julio-scpticmbre 1972).

ECHEVERRLA, Pedro Luis, CLAVE-

RIE RODRIGUEZ, Heliodoro L, y VILLALBA VERA, Jovito A.

El Tratado modificado de reciprocidad comercial entre Venezuela y los Estados Unidos.

Año V, No 19, p. 91 (julio-septicmbre 1972).

END, Heinrich

La política exterior del gobierno Kiesinger-Brandt.
Año II, No 17, p. 358 (octubre-diciembre 1968).

FAUNDEZ, Julio

El Sistema Interamericano de Seguridad en la política exterior de Estados Unidos.

No 11, p. 372 (octubre-diciembre 1969).

El presidente de Estados Unidos y la facultad para hacer la guerra.

Año IV, No 15, p. 60 (octubre-diciembre 1970).

FURTADO, Celso

La concentración del poder económico en los Estados Unidos y sus proyecciones en América.

No 3 y 4, p. 323 (octubre 1967-marzo 1968).

GODOY, Horacio $\mathrm{H}$.

Los Acuerdos entre los Estados Unidos y la Unión de las Repúblicas Socialistas Sovićticas.

Año VII, No 28 , p. 3 (octubre-diciembre 1974).

HANSEN, Roger

Relaciones económicas entre los Estados Unidos y América Latina. ¿Bilaterales, regionales o globales?

Año VIII, No 31, p. 59 (julio-septiembre I975).

HOFFMANN, Stanley

El estilo norteamericano: su pasado, sus principios.

Año III, $\mathrm{N}^{Q}$ 9, p. 48 (abril-junio 1969).

JAGUARIBE, Helio

El Vietnam y los Estados Unidos.

Año VIII, No 31, p. 3 (julio-septiembre 1975).

JOXE, Alain

¿Fin de la preponderancia estratègica norteamericana?

No 11, p. 273 (octubre-diciembre 1968).

MIHALY, Eugene B.

La estrategia de los Estados Unidos en el Pacífico Occidental y el dilcma de Micronesia.

Año $\mathrm{V}$, No 17, p. 25 (enero-marzo 1972).

PENA, Félix

EI Grupo Andino: un nuevo enfoque de la participación internacional de los paises en desarrollo. 
Año VI, No 22, p. 44 (abril-junio 1973).

SUNKEL, Osvaldo

Esperando a Godot: América Latina ante la nueva administración republicana de los Estados Unidos.

Año III, No 9, p. 23 (abril-junio 1969).

Relaciones económicas entre América Latina y Estados Unidos. Co. mentarios al trabajo de Anibal Pinto.

Año VI, Ne 22, p. 32 (abril-junio 1973).

TOMASSINI, Luciano

La misión imposible del presidente Nixon.

No 12, p. 512 (encro-marzo 1970).

VILLALBA VERA, Jovito A., CLAVERIE RODRIGUEZ, Helioloro L.

y ECHEVERRIA, Pcdro Luis

Ll ' 'ratado modificado de reciprocidad comercial entrc Venczucla y los Estados Unidos.

Año $\mathrm{V}, \mathrm{N}^{\circ} 19$, P. 91 (julio-septicmbre 1972).

\section{CANADA}

\section{CLARKSON, Stephen}

La intelligentsia satélite: los intelcctuales canadienses frente a los Estados Unidos.

Año V, No 18, p. 41 (abril-junio 1972).

OGELSBY, J. C. M.

Relaciones canadiense - latinoamericanas, pasadas, presentes y futuras.

Año V, No 18 , p. 68 (abril-junio 1972).

WATKINS, Melville $\mathbf{H}$.

Canadá: industria y propiedad extranjera.

Año III, No 10, p. 144 (julio scpticmbre 1969).

\section{EUROPA}

\section{BERNSIEIN, Enrique}

Situación política en vispera de mayo de 1968.

Año V, No 19, p. 103 (julio-septicmbre 1972).
DEVILLERS, Philippe

Francia y la Segunda Guerra del Victnam.

Año II, No 6, p. 214 (julio-septicmlue 1968).

END, Heinrich

La politica cxterior del gobierno Kie. singer-Brandt.

Año II. No 7, p. 358 (octubre-di(icmbre 1968).

FERRER, Aldo

Relacioncs económicas entre la Comunidlad Económica Europea y $\Lambda$ mérica Latina,

Aกัo VI, No 24, p. 3 (octubre-diciembre 1973).

JOXF, Alain

Hacia una nueva concepción de la scguridad europea.

Año I, No 2, p. 156 (julio 1967).

LOWENTHAL, Richard

Alcmania y el fin del sistema bipolar en la politica internacional.

N? 3 y 4, p. 411 (octubre 1967-marzo 1968).

MARTINS, Luciano

Mayo de 1968: una revolución nue. va $\mathrm{e}$ intransitiva.

Año III, No 10, p. 158 (julio-septicmbre 1969).

MERLINI, Cesare

La posición internacional de Italia. Oportunidades y tentaciones.

Año V, No 17, p. 76 (enero-marzo 1972).

OCLLSBX, J. C. M.

Relaciones canadiense-latinoamcricanas, pasadas, presentes y futuras.

Año V, No 18, p. 68 (abril-junio 1972).

VERNANT, Jacques

El mundo, Europa y Francia.

No 2, p. 123 (julio 1967).

YOUNGER, Kenneth

El papel de Gran Bretaña en la politica internacional.

No 2, p. 137 (julio 1967).

\section{CAMPO SOCIALISTA}

ACOSГA, Mercedes y VILAS, Carlos María

Santo Domingo y Checoslovaquia en la política de bloques, 
Año II, No 8, p. 565 (enero-marzo 1969).

BAMBIRRA, Vania

La Revolución Cultural y el Marxismo.

Año II, No 7, p. 406 (octubre-diciembre 1968).

BOGNAR, Jozsef

Reforma económica en Hungria.

Año III, No 10, p. 107 (julio-septiembre 1969).

GITTINGS, John

¿Tiene China una política exterior?

№ 1, p. 76 (abril 1967).

E1 Ejército Popular de Liberación y la Revolución Cultural,

Año II, No 5, p. 3 (abril-junio 1968). GODOY, Horacio $\mathrm{H}$.

Los Acuerdos entre los Estados Unidos y la Unión de las Repúblicas Socialistas Soviéticas.

Año VII, No 28, p. 3 (octubre-diciembre 1974).

KAISER, Karl

Una nueva política oriental en Alemania.

Año II, No 8, p. 543 (enero-marzo 1969).

VILAS, Carlos Maria y ACOSTA, Mercedes

Santo Domingo y Checoslovaquia en la política de bloques.

Año II, No 8, p. 565 (enero-marzo 1969).

\section{AFRICA}

GOTT, Richard

El sur de Africa y el fin de la guerra fría.

No 1, p. 95 (abril 1967).

El Congo a partir de Mobutu.

No 3 y 4, p. 443 (octubre 1967-marzo 1968).

MIRSKI, Gueorgui

El papcl político del ejército en los paises de Asia y Africa.

Año IV, No 13, p. 3 (abril-junio 1970).

MONETA, Carlos J.

Africa y los grandes actores externos.

Año VII, No 27, p. 31 (julio-septiembre 1974).

ORTIZ, Eduardo
Las grandes potencias y la crisis de Nigeria.

Año III, No 9, p. 352 (abril-junio 1969).

ASIA

ABERASTURY, Marcelo

Asia Oriental y Meridional y $\mathrm{cl} \mathrm{Pa-}$ cífico: Inicios de 1972.

Año V, No 17, p. 3 (enero-marzo 1972).

MIRSKI, Gueorgui

El papel político del ejército en los paises de Asia y Africa.

Año IV, No 13, p. 3 (abril-junio 1970).

SATHYAMURTHY, T. V.

Las relaciones internacionales asiáticas: Perspectivas contemporáneas.

Año IV, No 15, p. 3 (octubre-diciembre 1970).

WERTHEIM, W. F.

Indonesia antes y después del golpe de Untung.

No 3 y 4, p. 337 (octubre 1967-marzo 1968).

\section{VIETNAM}

DEVILLERS, Philippe

Francia y la Segunda Guerra del Vietnam.

Año II, No 6, p. 214 (julio-septiembre 1968).

GITTINGS, John

Libros sobre la guerra en Victnam.

No 2, p. 212 (julio 1967).

La nueva gucrra en Indochina.

Año IV, No 14, p. 104 (julio-septiembre 1970).

JAGUARIBE, Helio

El Vietnam y los Estados Unidos.

Año VIII, No 31, p. 3 (julio-septiembre 1975).

THOMSON, James C. Jr.

Victnam: un caso clínico.

Año II, Ne 7, p. 317 (octubre-diciembre 1968).

\section{EL PACIFICO}

ABERASTURY, Marcelo 
Asia Oriental y Meridional y el $\mathrm{Pa}$ cífico: Inicios de 1972.

Año V, No 17, p. 3 (enero-marzo 1972).

BALL, W. Macmahon

Australia en el Pacifico.

Año V, No 20, p. 40 (octubre-dicicmbre 1972).

BYTH, James

Niugini: una nueva nación cuprífera en el Pacifico se acerca a su independencia.

Año VI, No 22, p. 82 (abril-junio 1973).

FOGARTY, John

Australia y el problema de las inversiones extranjeras.

Año VI, No 22, p. 106 (abril-junio 1973).

GRANT, Bruce

Australia y cl Pacífico.

Año V, No 17, p. 40 (enero-marzo 1972).

KOJIMA, Kiyoshi

Un área de libre comercio del Pa- cífico.

Año V, No 20, p. 53 (octubre-diciembre 1972).

MIHALX, Eugene B.

La estrategia de los Estados Unidos en el Pacifico Occidental y el dilema de Micronesia.

Año V, No 17, p. 25 (enero-marzo 1972).

MILLAR, T. B.

Los Océanos Indico y Pacifico: Algunas consideraciones estratégicas.

No 11, p. 321 (octubre-diciembre 1969).

MONETA, Carlos Juan

Argentina y Australia: Esquemas para la cooperación.

Año VI, Ne 21, p. 55 (enero-marzo 1973).

TEITELBOIM, Sergio

Los paises del Pacífico Sur y el mar territorial.

Ario IV, No 16, p. 126 (enero-marzo 1971). 